Loma Linda University

TheScholarsRepository@LLU: Digital Archive of Research, Scholarship \& Creative Works

Loma Linda University Electronic Theses, Dissertations \& Projects

9-2017

\title{
Smoking, ADHD, and Problematic Video Game Use: A Structural Modeling Approach
}

Hyo Jin Lee

Follow this and additional works at: http://scholarsrepository.llu.edu/etd

Part of the Clinical Psychology Commons

\section{Recommended Citation}

Lee, Hyo Jin, "Smoking, ADHD, and Problematic Video Game Use: A Structural Modeling Approach" (2017). Loma Linda University Electronic Theses, Dissertations \& Projects. 441.

http://scholarsrepository.llu.edu/etd/441

This Thesis is brought to you for free and open access by TheScholarsRepository@LLU: Digital Archive of Research, Scholarship \& Creative Works. It has been accepted for inclusion in Loma Linda University Electronic Theses, Dissertations \& Projects by an authorized administrator of TheScholarsRepository@LLU: Digital Archive of Research, Scholarship \& Creative Works. For more information, please contact scholarsrepository@llu.edu. 


\section{LOMA LINDA UNIVERSITY \\ School of Behavioral Health \\ in conjunction with the \\ Faculty of Graduate Studies}

Smoking, ADHD, and Problematic Video Game Use: A Structural Modeling Approach

by

Hyo Jin Lee

A Thesis submitted in partial satisfaction of

the requirements for the degree

Doctor of Philosophy in Clinical Psychology

September 2017 
(C) 2017

Hyo Jin Lee All Rights Reserved 
Each person whose signature appears below certifies that this thesis in his/her opinion is adequate, in scope and quality, as a thesis for the degree Doctor of Philosophy.

, Chairperson

Holly E. R. Morrell, Associate Professor of Psychology

Colleen A. Brenner, Associate Professor of Psychology

Sylvia M. Herbozo, Associate Professor of Psychology 


\section{ACKNOWLEDGEMENTS}

I would like to express my gratitude to Dr. Morrell for her guidance and encouragement throughout this project. Your guidance made this project possible, and I really could not have done it without you. I appreciate all that you've done for me. I would also like to thank my committee members, Dr. Brenner and Dr. Herbozo. I am grateful for your support and guidance; your ideas and suggestions were crucial in making this project the best it can be. To my family, friends, and colleagues, I am thankful for your love and support. 


\section{CONTENT}

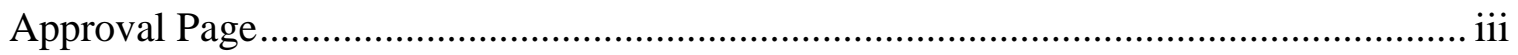

Acknowledgements ................................................................................................. iv

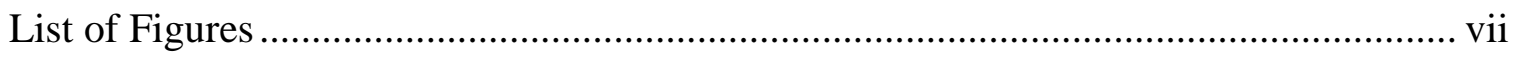

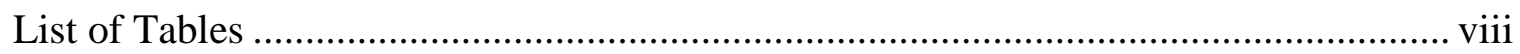

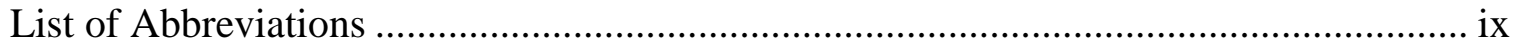

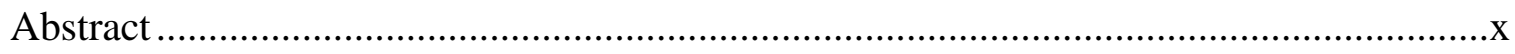

Chapter

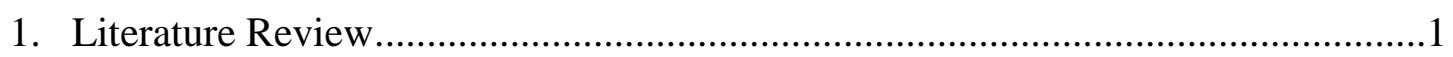

Video Games and Mental Health ...............................................................

Problematic Video Game Use.................................................................

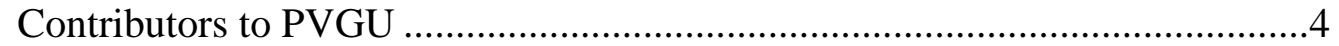

Limitations of Current Literature.................................................................

Aims and Hypotheses …………………………………........................11

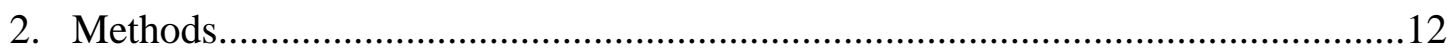

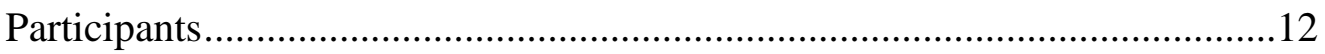

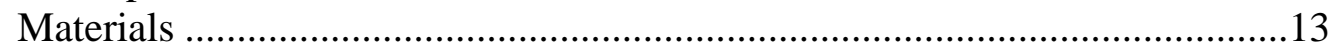

Demographic Variables ........................................................................13

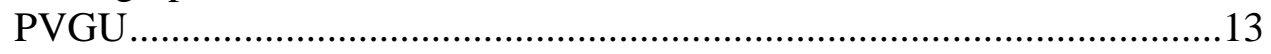

Young's Internet Addiction Scale, Adapted for Video

Game Use ..............................................................................13

Problem Videogame Playing Scale..............................................14

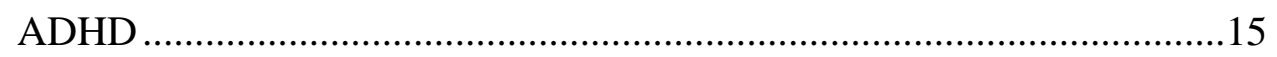

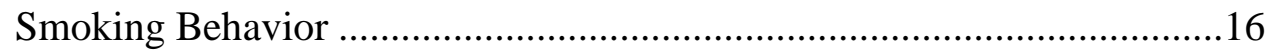

Hours of Video Game Use ...................................................................16

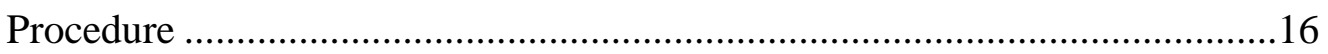

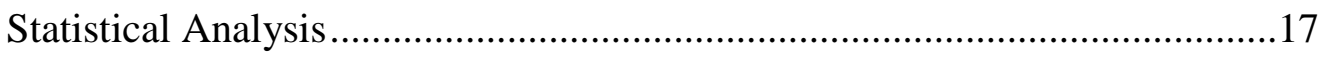

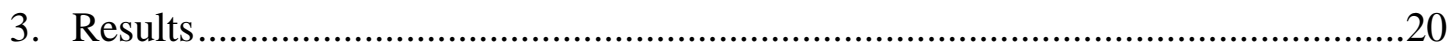


4. Discussion

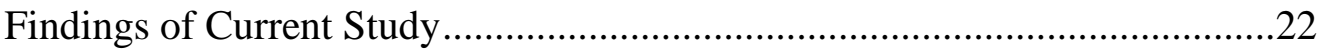

Conclusions and Implications ........................................................26

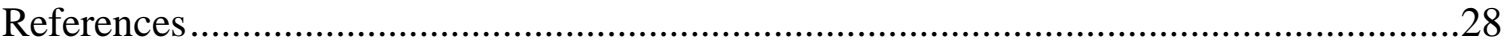




\section{FIGURES}

$\begin{array}{lll}\text { Figures } & \text { Page }\end{array}$

1. Full Structural Regression Model ............................................................. 17 


\section{TABLES}

Tables

Page

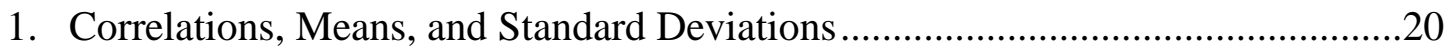




\section{ABBREVIATIONS}

PVGU

DSM-IV

DSM-5

ADHD

YIAS

PVP

CAARRS-S:S

WURS

SR

CFA

FIML

RMSEA

CFI

SRMR

CBT
Problematic video game use

Diagnostic and Statistical Manual of Mental Disorders $-4^{\text {th }}$

edition

Diagnostic and Statistical Manual of Mental Disorders $-5^{\text {th }}$

edition

Attention deficit hyperactivity disorder

Young's Internet Addiction Scale

Problem Videogame Playing Scale

Conner's Adult ADHD Rating Scale - Self-report: Short

Wender Utah Rating Scale

Structural regression

Confirmatory factor analysis

Full information maximum likelihood

Root Mean Square Error of Approximation

Conparative Fit Index

Standardized Root Mean Square Residual

Cognitive behavioral therapy 


\title{
ABSTRACT OF THE THESIS
}

Smoking, ADHD, and Problematic Video Game Use: A Structural Modeling Approach

\author{
by \\ Hyo Jin Lee \\ Doctor of Philosophy, Graduate Program in Psychology \\ Loma Linda University, March 2017 \\ Dr. Holly E. R. Morrell, Chairperson
}

Problematic video game use (PVGU), or addiction-like use of video games, is associated with negative physical and mental health problems as well as problems in social and occupational functioning. Possible contributors to PVGU include frequency of play, cigarette smoking, and ADHD. The aim of the current study was to explore the relationships among PVGU, cigarette smoking, ADHD, and frequency of play simultaneously using a structural modeling approach. Secondary data analysis was conducted on 2,801 video game users $\left(\mathrm{M}_{\mathrm{age}}=22.43\right.$ years, $\mathrm{SD}_{\mathrm{age}}=4.7 ; 93 \%$ male $)$ who completed an online survey comprising measures of PVGU, ADHD symptomatology, smoking behavior, and hours of video game use. The full model fit the data well: $\chi^{2}(2)=$ 2.017, $\mathrm{p}>.05 ; \mathrm{RMSEA}=0.002(90 \% \mathrm{CI}[.000, .038]) ; \mathrm{CFI}=1.000 ; \mathrm{SRMR}=.004$ Absolute values of all standardized residuals were less than 0.1. All freely estimated paths were statistically significant. ADHD symptomatology, smoking behavior, and hours of video game use explained $41.8 \%$ of variance in PVGU. ADHD symptomatology, cigarette use, and video game use may all contribute to PVGU, which is consistent with past studies that examined these variables independently. Tracking these variables may be useful for PVGU prevention and assessment. The measurement 
model fit well, suggesting that Young's Internet Addiction Scale, adapted for video game use, and Problem Videogame Playing Scale measure the same construct. Findings using either measures may be compared to each other, and both measures may be used as a screener of PVGU. The field of video game research may benefit from studying additional variables that help explain PVGU, specific treatment protocols for PVGU, and the effect of ADHD or smoking treatment on PVGU. 


\section{CHAPTER ONE}

\section{LITERATURE REVIEW}

\section{Video Games and Mental Health}

The video game industry has grown rapidly since 1958, when the first video game for recreational purpose was created (Brookhaven National Laboratory, 2008). The global games market was worth $\$ 83.6$ billion in 2014 , and is expected to reach $\$ 113$ billion by 2018 (Newzoo, 2015). "Minecraft," the title of a once-independent game currently owned by Microsoft, was the second most searched keyword on YouTube between 2012 and 2014 (Google, 2014). There are now 155 million Americans who report playing video games, with an average of two video game players in each game-playing U.S. household (Entertainment Software Assotiation, 2015). The idea of a stereotype video game player is now outdated, as the average individuals of both gender (56\% male, $44 \%$ female) and a wide range of ages (26\% under 18 years, 30\% 18-35 years, 17\% 36-49 years, 27\% 50 years or older) report video game use.

Video game players, as well as non-players, generally report a positive view of video game use (Entertainment Software Assotiation, 2015). Forty-seven percent of video game players report that computer and video games give them more value for their money than DVDs, music, or going out to the movies. Sixty-three percent of parents consider video games as a positive part of their child's life. Forty-two percent of parents play video games with their child at least weekly; some of the reasons that parents cite are that video games are fun for the entire family $(88 \%)$, they are asked to play by their child (84\%), and it is a good opportunity to socialize with their child (75\%)

(Entertainment Software Association, 2014). 
In response to the growth and popularization of video games, researchers have begun examining the effects of video games on the player in the last twenty years. Depending on the content, certain video games may enhance visual spatial skills, problem-solving skills, and performance on reaction time tests (Schmidt \& Vandewater, 2008). Researchers are also exploring the therapeutic use of video games. For example, some neurofeedback systems that help patients manage ADHD symptoms by reinforcing rapid neural communications present data to the user in the format of a video game (Butnik, 2005).

Despite its benefits, video game use can also be associated with harmful consequences. Similarly to exposure to media violence, exposure to violent video games increases the risk of desensitization to violence (Brockmyer, 2015). In a longitudinal study with nine to 18 year olds, individuals who played at least some violent video games in the past year had four times greater odds of carrying a weapon to school in the last month (Ybarra, Huesmann, Korchmaros, \& Reisner, 2014). In another study, time spent playing video games was a significant predictor of severe symptoms of depression and anxiety (Maras et al., 2015).

\section{Problematic Video Game Use}

Addiction is another potential negative consequence of video game use. Goodman (1990) defined addiction as engagement in behavior that is either pleasurable or reliefinducing, without having control over the behavior and despite experiencing significant negative consequences. Although addiction has traditionally been studied with substancerelated behavior, uncontrollable video game use that yields significant negative 
consequences may also be considered as a form of addiction. While video game addiction is not a formal diagnosis in the Diagnostic and Statistical Manual of Mental Disorders 5th edition (DSM-5), Internet Gaming Disorder is listed under the section "Conditions for Further Study," encouraging research in this area (American Psychiatric Association, 2013). In addition, studies show that the biological mechanisms for behavioral addictions are similar to the biological mechanisms of substance addictions (Kuss \& Griffiths, 2012). Addiction-like video game use is characterized by an overall reward deficiency and, similar to substance dependence, cue-induced craving is present in both internet and gaming addiction.

Some researchers studying video game addictions employ diagnostic criteria for pathological gambling from the Diagnostic and Statistical Manual of Mental Disorders 4th edition (DSM-IV-TR; American Psychiatric Association, 2000) adapted for video game use (Coëffec et al., 2015; Gentile et al., 2011; Ream, Elliott, \& Dunlap, 2011b; Weinstein \& Weizman, 2012). Others study problematic video game use (PVGU), which is a more general term that may refer to a large number of hours of video game use per day (Wenzel, Bakken, Johansson, Götestam, \& Øren, 2009), or to high scores on questionnaires designed to measure addiction-like use of video games (Ream et al., 2011b; Van Rooij et al., 2014; Walther, Morgenstern, \& Hanewinkel, 2012). Because the discussion on video game addiction is still in progress, this paper will mainly use the term PVGU to refer to addiction-like or problematic use of video games.

Regardless of the way PVGU is measured, research indicates that PVGU is associated with a number of negative consequences. Some video game players report spending too much time playing video games (Ng \& Wiemer-Hastings, 2005), having 
difficulty cutting back on gaming, and experiencing an irresistible urge to play (Desai, Krishnan-Sarin, Cavallo, \& Potenza, 2010), all of which describe video game use that is out of control. Some video game players also report general health and mental health problems (Wenzel et al., 2009). In a longitudinal study, Gentile et al. (2011) found that PVGU was a significant predictor of depression, anxiety, and social phobia. Van Rooij et al. (2014) also found that PVGU was associated with a number of negative mental health conditions, such as depressive mood, loneliness, social anxiety, and negative self-esteem. Some players report adverse consequences with school work (Gentile et al., 2011; Van Rooij et al., 2014; Wenzel et al., 2009), jobs, and close relationships as a result of PVGU (Wenzel et al., 2009). In terms of prevalence, Gentile (2009) found that $8.5 \%$ of youths in the U.S. between 8-18 years of age engaged in pathological video game use. Similar prevalence rates have been observed in other countries, including Taiwan (7.5\%; Ko, Yen, Yen, Lin, \& Yang, 2007), Germany (11.9\%; Grüsser, Thalemann, \& Griffiths, 2007), Singapore (7.6-9.9\%; Gentile et al., 2011), and in an online survey (8\%; Porter, Starcevic, Berle, \& Fenech, 2010).

\section{Contributors to PVGU}

Due to these potential problems, it is important to identify the contributors to PVGU. A primary contributor to PVGU is the amount of video game use. A large amount of video game use may be indicative of behavior that is out of control and may lead to negative consequences in a number of areas. Individuals who play video games most often tend to play the longest sessions, and the majority of those who play over four hours per session tend to play video games every day (Griffiths \& Hunt, 1995). Ream et 
al. (2011b) found that video gaming as an enthusiastic hobby, defined as the number of days spent playing video games in the last 30 days, was positively associated with PVGU. In addition, Coëffec et al. (2015) found that individuals with PVGU tend to spend more time on video games compared to individuals without PVGU.

Cigarette smoking may be another contributor to PVGU. Substance use, including tobacco use and behavioral addictions, tend to be correlated with each other (Desai et al., 2010; Ream et al., 2011b; Van Rooij et al., 2014; Walther et al., 2012). Walther et al. (2012) found a significant co-occurrence between problematic gambling and tobacco, alcohol, and cannabis use, with correlations ranging between 0.13 and 0.15 . Ream et al. (2011b) found that among adults 18 years or older, PVGU was correlated with problematic use of all of the addictive substances studied, including tobacco, with correlations ranging between 0.22 and 0.33 . Desai et al. (2010) found that among adolescents, when adjusting for race and gender, the odds of reporting PVGU were $112 \%$ greater for video game players who reported smoking regularly compared to video game players who reported never having smoked ( $\mathrm{p}$.007). In addition, Van Rooij et al. (2014) found that for boys, those who used cigarettes, alcohol, or cannabis were twice as likely to score high on PVGU.

A potential explanation for the relationship between smoking and PVGU is the self-medication hypothesis. The self-medication hypothesis describes substance use and dependence as an individual's attempt to relieve suffering, and holds that an individual's preference for a particular substance is at least partially based on the type of distress being addressed (Mariani, Khantzian, \& Levin, 2014). The co-occurrence of PVGU and smoking may be a way for users to negate the adverse consequences or enhance the 
positive consequences of each behavior. For example, Ream, Elliott, and Dunlap (2011a) found through an exploratory factor analysis that motivations for concurrent use of video games and addictive substances included passing time or regulating negative emotion, enhancing a positive experience of video games through substance use, and using video games and substances to remediate each other's undesirable effects, such as game-related frustration or hangovers and other substance withdrawals.

Attention deficit hyperactivity disorder (ADHD) may also contribute to PVGU. Few studies have examined the relationship between ADHD and electronic media other than TV (Schmidt \& Vandewater, 2008), but those that do tend to find a significant positive relationship between ADHD and PVGU. That is, ADHD or ADHD symptoms are significant predictors of increased video game use (Chan \& Rabinowitz, 2006; Lingineni et al., 2012) or more problematic behavior associated with video games (Weinstein \& Weizman, 2012; Weiss, Baer, Allan, Saran, \& Schibuk, 2011). While Bioulac, Arfi, and Bouvard (2008) found no difference between children with ADHD and children without ADHD on frequency or duration of video game use, children with ADHD in that study had significantly higher PVGU scores than children without ADHD. In addition, children with ADHD were less likely to stop playing video games on their own, less likely to stop playing when asked by their parents to stop, and more likely to exhibit negative emotions when they had to stop playing.

In addition to directly contributing to PVGU, ADHD may also indirectly contribute to PVGU through its relationship with smoking. That is, ADHD may contribute to smoking, which then contributes to PVGU. Adolescents and young adults with ADHD have a significantly greater chance of smoking compared to those without 
ADHD (Glass \& Flory, 2010). The comorbidity between ADHD and smoking may be at least partly due to genetic variations; candidate gene studies have identified several dopamine and serotonin gene variants that are associated with higher levels of both ADHD and smoking (McClernon \& Kollins, 2008).

A meta-analysis of seven studies showed that smokers with childhood history of ADHD begin to regularly smoke earlier than smokers without childhood history of ADHD (Standardized Mean Difference $=-0.28,95 \% \mathrm{CI}=[-0.49,-0.07], \mathrm{p}<0.02 ;$ Fond et al., 2014). That is, the mean difference between smokers with ADHD history and smokers without ADHD history were significantly different, such that the age at regular smoking onset was 0.28 standard deviations younger for smokers with ADHD history. A closer examination of the individual studies included in the meta-analysis by Fond et al. (2014) that reported significant findings reveals that two of the studies reported a significant relationship between ADHD and smoking. Matthies et al. (2013) found that adults with ADHD started smoking at a younger age compared to individuals without ADHD, and Laucht, Hohm, Esser, Schmidt, and Becker (2007) found that adolescents with ADHD have higher rates of smoking activity compared to adolescents without ADHD. Most of the studies included in Fond et al. (2014) did not report significant differences in age of regular smoking onset between smokers with childhood history of ADHD and smokers without childhood history of ADHD (Covey, Manubay, Jiang, Nortick, \& Palumbo, 2008; Fond et al., 2015; Humfleet et al., 2005; Kollins, McClernon, \& Van Voorhees, 2010; McClernon et al., 2011). The lack of significant findings may be explained by the fact that two of these studies had small sample sizes $(\mathrm{N}=22$, Kollins et al., 2010; $\mathrm{N}=40$, McClernon et al., 2011) and three of these studies measured current 
symptoms of ADHD, which may or may not actually indicate past ADHD

symptomatology (e.g., prior to successful medication management) that would have facilitated nicotine use (Covey et al., 2008; Kollins et al., 2010; McClernon et al., 2011). Nevertheless, combining these studies using meta-analytic techniques revealed a significant relationship between ADHD and age at onset of regular smoking.

The self-medication hypothesis may also help explain the co-occurrence of ADHD and smoking. As described previously, the self-medication hypothesis posits that an individual uses an addictive substance in order to relieve suffering, and that the specific substance that is chosen is intended to address the specific type of distress being experienced (Mariani et al., 2014). Lerman et al. (2001) found that stimulation seeking as a motive for smoking, such as seeking alertness or lift in mood, was positively related to levels of inattention symptoms in a non-patient sample, as measured by a self-report scale of inattention symptoms based on ADHD criteria from DSM-IV (American Psychiatric Association, 2000). Smoking for stimulation explained significant variation in total ADHD symptom severity. Gehricke, Whalen, Jamner, Wigal, and Steinhoff (2006) found that when smokers with ADHD refrained from smoking, difficulty concentrating and daydreaming were reduced when either nicotine patches, stimulant medication, or the combination of the two were used. Thus, smoking may be a way to improve attention and concentration, which is a deficit in individuals with ADHD.

Gehricke, Hong, Whalen, Steinhoff, and Wigal (2009) studied the effect of nicotine on ADHD symptoms in smokers and nonsmokers with ADHD. Both smokers and nonsmokers were studied in order to test for withdrawal relief, since some nicotine withdrawal symptoms such as difficulty concentrating and restlessness are also typical 
symptoms of ADHD, and alleviation of these symptoms through nicotine use may be mistaken for ADHD symptom reduction. Nonsmokers would not experience withdrawal relief, and therefore a difference in ADHD symptom alleviation between smokers and nonsmokers would indicate that the effect may actually be partially due to withdrawal relief. Results of this study indicated that use of the nicotine patch compared to a placebo patch significantly improved ADHD symptoms by approximately $8 \%$ (ps $<.02$ ), with no nicotine by smoking status interaction, offering evidence to support the idea that smoking specifically addresses ADHD symptoms.

Impulsivity may also help explain the relationship between ADHD and PVGU. Impulsivity is one of the key descriptors of ADHD (Centers for Disease Control and Prevention, 2016), and is a major component in diagnosis of ADHD according to DSM-5 (American Psychiatric Association, 2013). Impulsivity is also characteristic of PVGU; Walther et al. (2012) found that problematic gamers score higher on an ADHD personality factor as well as a separate measure of impulsivity. Specifically, individuals with high impulsivity have 79\% greater odds of engaging in PVGU than individuals with low impulsivity $(\mathrm{OR}=1.79,95 \% \mathrm{CI}=[1.10-2.93])$. Video games may reinforce quick responsiveness and need for immediate reward, and the prolonged use of video games may further encourage impulsiveness (Weiss et al., 2011). In addition to impulsivity being a risk factor for PVGU, PVGU may also worsen impulsivity, exacerbating the problem (Gentile et al., 2011).

\section{Limitations of Current Literature}

As video games are a more recent phenomenon, studies on video games in 
general, as well as PVGU more specifically, are few in number. Because there is no accepted definition for problematic use of video game, different studies conceptualize and define PVGU differently. For example, several studies measure "screen time" by combining video game use with computer use and/or TV use (Maras et al., 2015; Shi \& Mao, 2011). This makes it difficult to discern whether the findings of these studies can be attributed to the use of video games alone or to screen time in general. The measurement tools for video game use also vary among different studies. As discussed above, researchers may measure PVGU based on diagnostic criteria for pathological gambling from the DSM-5, high scores on questionnaires measuring addiction-like use of video games, or simply large number of hours of video game use. This lack of uniformity in measurement makes it difficult to compare the results of existing studies.

The lack of research on PVGU and the methodological limitations of existing studies make it difficult to make recommendations for both the prevention and treatment of PVGU, even though problematic play is associated with negative life consequences in a substantial subset of gamers (Brockmyer, 2015; Maras et al., 2015; Ybarra et al., 2014). Current treatment recommendations for PVGU, such as cognitive-behavior therapy (Griffiths \& Meredith, 2009) and family therapy (Young, 2009), are therefore based on limited information and actual treatment studies are few in number (Griffiths \& Meredith, 2009; Pallesen, Lorvik, Bu, \& Molde, 2015). Identifying the relationships among contributors to PVGU is critical for the development of appropriate treatment plans specific to PVGU, as well as to help assess risk and develop prevention programs for populations that may be more vulnerable to PVGU (e.g., individuals with ADHD and/or smokers). 


\begin{abstract}
Aims and Hypotheses
The overarching aim of the current study is to explore the relationships among contributing factors to video game addiction. Current literature suggests that ADHD, nicotine use, and number of hours spent on video games are all independently associated with video game addiction. However, research on video game use and addiction is sparse, and no study has examined all of these factors simultaneously yet. Investigating such relationships may enhance understanding of the mechanisms by which these potential risk factors may lead to video game addiction. Also, limitations in the field will be addressed in this study. Specifically, variability in measurement for PVGU will be addressed by including two measures for PVGU using structural regression. We hypothesize that presence of adult ADHD symptomatology will be associated with a greater risk for video game addiction, both directly and indirectly through nicotine use and number of hours spent on video games. We also hypothesize that nicotine use will be associated with a greater risk for video game addiction, both directly and indirectly through number of hours spent on video games. Finally, we hypothesize that greater number of hours spent playing video games will be associated with a greater risk for video game addiction.
\end{abstract}




\section{CHAPTER TWO}

\section{METHODS}

\section{Participants}

Data used were originally collected for a study exploring the relationship between video game addiction, ADHD, and the addictive nature of different game genres. The sample included 2,801 video game users who responded to online advertisements on multi-genre video game forums for an online survey. All individuals were adults between the ages 18 and $57(M=22.43, S D=4.70 ; 93 \%$ male $)$. In terms of ethnicity, $8.2 \%$ of participants reported being of Hispanic or Latino descent. The racial breakdown was as follows: $82.3 \%$ Caucasian, $7.6 \%$ Asian or Asian American, $4.7 \%$ identifying as Other, $3.5 \%$ identifying as mixed race, $0.6 \%$ Native American or Alaskan Native, $0.4 \%$ Black or African American, and 0.3\% Native Hawaiian or other Pacific Islander. The majority of the sample (48.6\%) resided in the United States; the rest resided primarily in other developed countries such as Canada (8.5\%), Sweden (4.6\%), and Germany (4.2\%).

Sixty point eight percent were students, $25.3 \%$ were employed full time, $7.7 \%$ were unemployed, and $6.1 \%$ were employed part time. The educational levels were as follows: $36.3 \%$ reported having completed some college, $19.8 \%$ reported obtaining an undergraduate degree, $18.4 \%$ reported obtaining a high school diploma or GED, 10.6\% reported obtaining a graduate degree, $8.6 \%$ reported completing some high school, and 5.8\% reported completing some graduate education. The majority of the sample were single (62.2\%); $29.3 \%$ were dating, $7.5 \%$ were married, $0.3 \%$ were divorced, $0.3 \%$ were widowed, and $0.2 \%$ were separated. 


\section{Materials}

\section{Demographic Variables}

Participants were asked for the following demographic information: age, gender, ethnicity, and socioeconomic status.

\section{$P V G U$}

\section{Young's Internet Addiction Scale, Adapted for Video Game Use}

Young's Internet Addiction Scale (YIAS; Young, 1998) is a 20-item scale intended to assess Internet addiction among adults. It adapts DSM-IV criteria for pathological gambling to Internet addiction. All items are on a six-point Likert scale $(0=$ not at all, $1=$ rarely, $2=$ occasionally, $3=$ frequently, $4=$ often, and $5=$ always), and the scores are combined to form a total score that ranges between 0 and 100. Scores between 0 and 30 indicate a normal level of Internet use. Scores between 31 and 49 indicate a mild level of Internet addition. Scores between 50 and 79 indicate a moderate level of Internet addiction. Scores between 80 and 100 indicate a severe level of Internet addiction. For this study, all uses of the word "Internet" were replaced with "video game(s)" to adapt the questionnaire for measuring video game addiction. Example items include "How often do you prefer the excitement of video games to intimacy with your partner?" and "How often does your job performance or productivity suffer because of playing video games?"

Widyanto and McMurran (2004) found that the YIAS comprises six factors: salience, excess use, neglect of work, anticipation, self-control, and neglect of social life. They found that internal reliability varied, with Cronbach's standardized alphas ranging 
between 0.54 and 0.82 . Also, the six factors significantly correlate with each other, with Pearson's rs ranging from 0.23 to 0.62 . Chan and Rabinowitz (2006) reported that YIAS, adapted for video game use, has a reliability of 0.82 . The Cronbach's alpha calculated with the current sample was 0.89 .

\section{Problem Videogame Playing Scale}

Problem Videogame Playing Scale (PVP; Tejeiro Salguero \& Bersabé Morán, 2002) is a nine-item scale intended to assess symptoms of video game addiction. It is based on DSM-IV criteria for substance dependence and pathological gambling. Criteria measured include negative consequences; loss of control; tolerance; deception; withdrawal; escape; dysfunction in social, educational, and occupational areas; and a disregard for negative consequences. The items are dichotomous, with yes or no answers; higher total scores indicate higher levels of PVGU. Example items include "I spend an increasing amount of time playing video games" and "When I lose in a game or I have not obtained the desired results, I need to play again to achieve my target.”

Tejeiro Salguero and Bersabé Morán (2002) found that the internal reliability for the PVP is acceptable, with a Cronbach's alpha of 0.69. They determined that the scale had good construct validity based on a high, significant correlation between PVP score and the frequency of video game play, mean duration of video game play, and longest time per session, with Spearman's rs ranging between 0.52 and 0.64 . The Cronbach's alpha calculated with the current sample was 0.53 .

For this study, an eight-item version of the original scale was used. One item was excluded from the scale due to error, and no data were collected for this item. The item 
excluded is the following: "Because of the video game playing I have reduced my homework, or schoolwork, or I have not eaten, or I have gone to bed late, or I spent less time with my friends and family."

\section{$A D H D$}

Conners’ Adult ADHD Rating Scale- Self-Report: Short (CAARS-S:S; Conners, Erhardt, Epstein, Parker, \& Sitarenios, 1999) is a 26-item scale intended to assess ADHD symptomatology in adults. Factor-derived subscales include Inattention, Hyperactivity/Restlessness, Impulsivity/Emotional Liability, and Problems with SelfConcept. All items are on a four-point Likert scale $(0=$ not at all; $1=$ just a little, once in a while; 2 = pretty much, often; and 3 = very much, very frequently), and the scores are combined to form a total score that ranges between 0 and 78 . An overall score of greater than 65 is considered to reflect a clinically significant level of ADHD symptomatology (Rösler et al., 2006). Example items include "It's hard for me to stay in one place very long" and "I intrude on others' activities."

Erhardt, Epstein, Conners, Parker, and Sitarenios (1999) found that the internal reliability of the CAARS-S:S ranges from good to excellent, with coefficient alphas for the four factors ranging between .86 and .92 for both males and females, and between all age groups measured (18-29 year-olds, 30-39 year-olds, 40-49 year-olds, 50 years-old and older). In addition, test-retest correlations range between 0.80 and 0.91 . Compared to the Wender Utah Rating Scale (WURS; Ward, Wender, \& Reimherr, 1993), a retrospective self-report scale on childhood ADHD symptomatology, the correlations 
among WURS total score and all CAARS factors were significant. The Cronbach's alpha calculated with the current sample was 0.89 .

\section{Smoking Behavior}

Smoking behavior was measured by asking participants to report the number of cigarettes smoked per week.

\section{Hours of Video Game Use}

Hours of video game use was measured by asking the participants the number of hours spent playing video games per week.

\section{Procedure}

The original study was approved by Internal Review Board of Loma Linda University for the use of human participants. All individuals were treated in accordance with the American Psychological Association's ethical guidelines.

After receiving approval, a survey was created through Qualtrics, a website that hosts online questionnaires and employs a sufficient level of security to prevent survey tampering. A link to the survey, as well as a basic statement explaining the purpose of the study and the researcher's email address for questions, was included in the advertisements for the study. The advertisements were posted on multi-genre web forums such as Reddit.com, World of Warcraft game blogs, SomethingAwful.com, and PennyArcade.com. In-game advertisements were also posted.

The first page of the survey informed the participants of the purpose of the study, the voluntary nature of their participation, and their right to withdraw at any time. After 
consenting to the study, the participants were asked to provide demographic information, followed by a battery of self-report measures. No incentives were offered for participation.

\section{Statistical Analysis}

A partially latent SR model was used to test the relationships among ADHD, nicotine use, number of hours spent on video games, and problematic video game use (PVGU). In the structural component of the model, ADHD, nicotine use, and number of hours spent on video games were tested as predictors of PVGU. In the measurement component of the model, PVGU was a latent variable, defined by the YIAS adapted for video games and the PVP scale. The YIAS, which has higher reliability than the PVGU, was used to set the metric. See Figure 1 for a model of the hypothesized relationships that were tested.

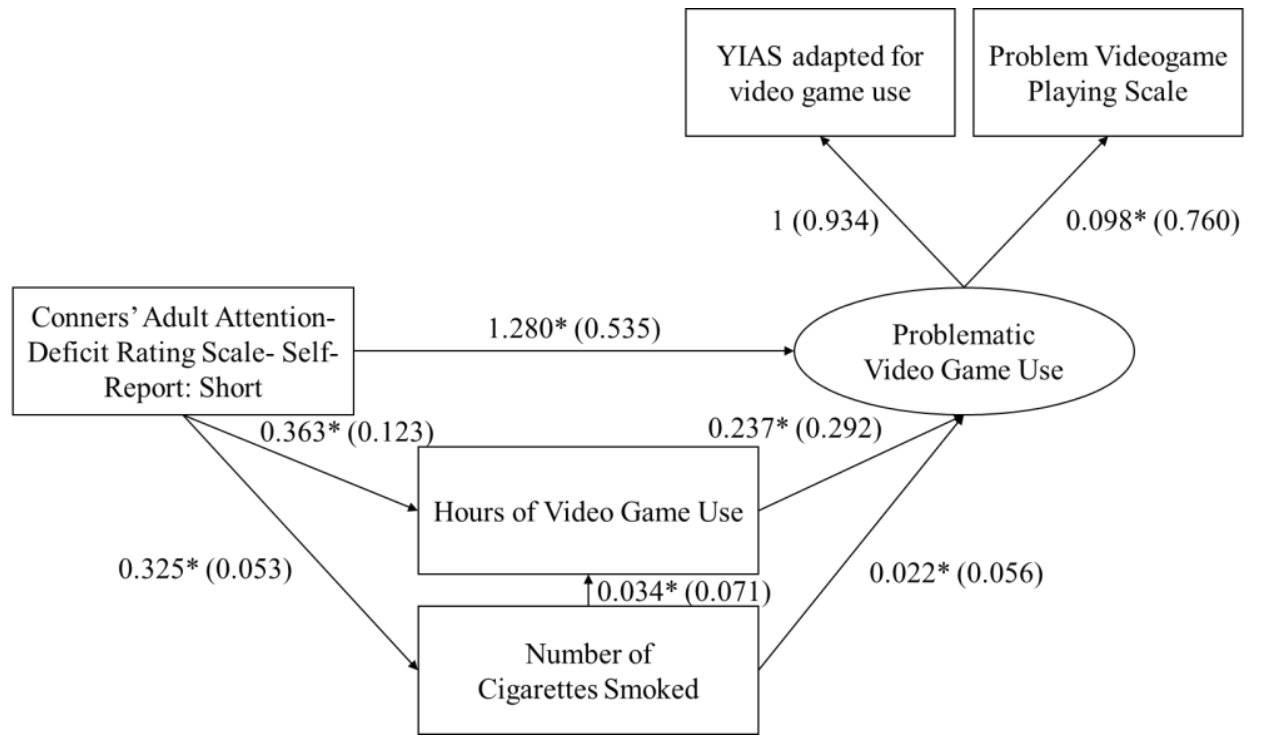

Figure 1. Full structural regression model predicting problematic video game use from ADHD symptomatology, hours of video game use, and smoking behavior. Standardized values are in parentheses. All freely estimated paths were significant. ${ }^{*} p<0.05$. 
A structural regression (SR) model consists of two components: a confirmatory factor analysis (CFA) model, also called measurement model, and a path model, also called structural model (Kline, 2005). Because it contains both the measurement and the structural components, it can be used to explore relationships among observed variables as well as the factors underlying those variables. When at least one variable in the structural part of the model is only measured using one variable, the model is said to be a partially latent SR mode

The model must first be identified before it can be analyzed (Kline, 2005). A twostep rule can be used to ensure identification of the entire model. First, the measurement model must have at least two measured variables for every factor, and the metric must be set every factor. If the model is a single factor model, there must be at least three indicators. Second, the structural model must be recursive. In a recursive model, all causal effects are unidirectional, and none of the disturbances are correlated. If the model meets both of these rules, the model is identified and can be analyzed. The model proposed in this study meets the second requirement, but not the first; the model is a single factor model, and only has two indicators. An unidentified model can produce an infinite number of different solutions. In order to check if the solution produced by the model is unique, the analysis was re-run with different start values. The model did not converge to a different solution, indicating that the solution is unique for this model (Kline, 2005).

The initially proposed method of testing model fit was a two-step modeling process, in which the fit of the measurement model is tested before the fit of the full SR model is tested. However, the measurement model by itself was not identified, ruling out 
the two-step modeling process. An SR model can be analyzed in several different ways, including but not limited to two-step modeling (Kline, 2005). For this analysis, the full SR model was analyzed in a one-step modeling process given that the measurement model was not independently identified.

The analysis was conducted using EQS Version 6.1 with full information maximum likelihood (FIML) estimation. Instead of the traditional approach to handling missing data in SEM, which involves deleting all cases with any missing information, FIML allows all available data to be used, even if some data in a case may be missing. The following indices were used to assess model fit: model chi-square $(\chi 2)$, Root Mean Square Error of Approximation (RMSEA), Comparative Fit Index (CFI), and Standardized Root Mean Square Residual (SRMR). Good fit is indicated by a nonsignificant $\chi 2$, RMSEA $<.05$ with the upper limit of the $90 \% \mathrm{CI}<.1, \mathrm{CFI}>.9$, SRMR < .1, and absolute values of standardized residuals < .1. Lagrange Multiplier and Wald tests were evaluated to identify potential changes to the model that might improve fit, if necessary. The Lagrange Multiplier test assesses whether the model can be significantly improved by adding parameters. The Wald test assesses whether parameters can be deleted without significantly reducing model fit. 


\section{CHAPTER THREE}

\section{RESULTS}

Table 1 shows the correlations, means, and standard deviations of all variables.

Results of model testing are shown in Figure 1. The full model fit the data well: $\chi^{2}(2)=$ $2.017, \mathrm{p}>.05 ; \mathrm{RMSEA}=0.002(90 \% \mathrm{CI}[.000, .038]) ; \mathrm{CFI}=1.000 ; \mathrm{SRMR}=.004$.

Absolute values of all standardized residuals were less than 0.1. Given that the model fit the data well, no changes to the model were necessary.

Table 1. Correlations, Means, and Standard Deviations

\begin{tabular}{llcccrrr}
\hline & 1 & 2 & 3 & 4 & 5 & $M$ & $S D$ \\
\hline CAAR & 1 & & & & & 11.168 & 5.560 \\
Hours of Video Game Use & $0.124^{* *}$ & 1 & & & 25.991 & 16.391 \\
Smoking & 0.053 & $0.080^{* *}$ & 1 & & & 13.067 & 33.968 \\
YIAS & $0.535^{* *}$ & $0.352^{* *}$ & $0.083^{* *}$ & 1 & & 31.711 & 14.287 \\
PVP & $0.441^{* *}$ & $0.263^{* *}$ & $0.095^{* *}$ & $0.712^{* *}$ & 1 & 2.691 & 1.721 \\
\hline
\end{tabular}

${ }^{*} p<.05,{ }^{* *} p<.01$

As hypothesized, there was a significant positive relationship between ADHD symptomatology and smoking behavior, such that for every one-point increase in ADHD symptomatology, participants reported smoking an additional one-third of a cigarette per week $(b=0.325, p<.05)$. There was also a significant positive relationship between ADHD symptomatology and video game use, such that for every one point increase in ADHD symptomatology, video game use increased by about 22 minutes per week $(b=$ $0.363, \mathrm{p}<.05)$. There was also a significant positive relationship between ADHD symptomatology and problematic video game use, such that for every one point increase in ADHD symptomatology, PVGU increased by 1.280 points $(\mathrm{p}<.05)$. 
There was a significant positive relationship between smoking behavior and video game use, such that for every additional cigarette smoked, video game use increased by two minutes $(\mathrm{b}=.034, \mathrm{p}<.05)$. There was also a significant positive relationship between smoking behavior and PVGU, such that for every additional cigarette smoked, PVGU increased by 0.022 points $(\mathrm{p}<.05)$. Finally, there was a significant positive relationship between video game use and PVGU, such that for every additional hour of video game use, PVGU increased by 0.237 points $(\mathrm{p}<.05)$.

ADHD symptomatology explained $0.3 \%$ of variance in smoking behavior. ADHD symptomatology and smoking behavior together explained $2.1 \%$ of variance in video game use. ADHD symptomatology, smoking behavior, and video game use together explained $41.8 \%$ of variance in problematic video game use. In terms of the measurement model, the YIAS and PVP both loaded significantly and positively onto the PVGU factor. Specifically, the standardized factor loading for YIAS was 0.934 , and the standardized factor loading for PVP was 0.760. 


\section{CHAPTER FOUR \\ DISCUSSIONS}

\section{Findings of Current Study}

The goal of the current study was to explore the relationships among contributing factors to problematic video game use (PVGU). The proposed model fit the data well, with no respecification necessary. All hypothesized relationships were statistically significant; ADHD, cigarette use, and video game use had significant positive relationships with each other and with PVGU. In particular, the data suggest that ADHD symptomatology, cigarette use, and video game use may all contribute to problematic or addictive use of video games; together, ADHD, smoking, and video game use explained 41.8\% of the variance in PVGU. This finding is consistent with previous studies, which examined the effect of ADHD symptomatology (Bioulac et al., 2008; Weinstein \& Weizman, 2012; Weiss et al., 2011), smoking (Desai et al., 2010; Ream et al., 2011b; Van Rooij et al., 2014), and video game use (Coëffec et al., 2015; Ream et al., 2011b) on PVGU, but all independent of each other.

The current study also allowed us to test whether the YIAS and PVP were measuring the same construct, which is important when determining whether results from studies using only one of these measures are comparable. Their factor loadings were significantly strong, suggesting that both scales are measuring PVGU, and either one can be used to assess for PVGU. The PVP, a nine-item scale, may be useful when a quick screening instrument is needed, while the YIAS, a 20-item scale, may be more helpful in capturing a wider range of the severity of PVGU. The fact that these two scales exhibited strong factor loadings on PVGU in the current study also suggests that findings from 
existing studies using either one of these two instruments may be more readily compared to each other.

The relationships among the contributing factors of PVGU each have a varying degree of clinical impact. That is, despite their statistical significance, some of the relationships tested in this model may be more clinically significant than others. ADHD symptomatology explained $0.3 \%$ of variance in smoking behavior, and ADHD symptomatology and smoking behavior together explained $2.1 \%$ of variance in video game use. These effect sizes are small, suggesting weak clinical significance. Research suggests a significant level of comorbidity between ADHD and smoking (Glass \& Flory, 2010; Laucht et al., 2007), as well as the tendency for individuals with history of ADHD to start smoking regularly earlier than individuals without history of ADHD (Fond et al., 2014; Matthies et al., 2013). However, it could be that ADHD symptomatology only weakly explains smoking behavior because there is some other underlying factor that influences both ADHD and smoking behavior. For example, candidate gene studies suggest that there may be some genetic explanation for both high levels of ADHD and smoking (McClernon \& Kollins, 2008). In addition, there may be other variables that better predict video game use, such as negative self-esteem (Walther et al., 2012), lower social competence (Gentile et al., 2011), and reinforcement characteristics of the video game (Chumbley \& Griffiths, 2006).

There may be other variables that are not included in the current model that better predict PVGU. For example, feelings of loneliness are commonly studied in both video game and substance use research. Individuals with PVGU report significantly higher levels of loneliness compared to individuals without PVGU (Van Rooij et al., 2014; 
Walther et al., 2012), and individuals who play multiplayer online games also report significantly higher levels of loneliness compared to individuals who do not play online games, regardless of the intensity of use (Van Rooij et al., 2014). At the same time, loneliness also seems to be related to smoking (Dyal \& Valente, 2015) and thus may be a motivating factor for concurrent use of video games and use of substances such as alcohol or tobacco (Ream et al., 2011a). Incorporating a variable such as loneliness into models predicting PVGU may explain additional variance in PVGU, particularly among individuals who use video games for social interaction through multi-player games and in-game chat rooms.

While the individual contributors to PVGU were associated with small effect sizes, the effect of the combined predictors on PVGU was large. ADHD symptomatology, smoking behavior, and video game use together explained $41.8 \%$ of variance in PVGU. This is likely to be a clinically significant relationship. Considering these multiple factors in combination when approaching the assessment and treatment of PVGU may help in understanding and making appropriate treatment plans for individuals who report PVGU. For example, clinicians who are treating clients with PVGU may benefit from tracking not only the amount of video game use, but also clients' smoking behavior and their current ADHD symptomatology. In addition, clinicians whose clients show high levels of ADHD symptomatology, cigarette use, and video game use may consider also assessing for PVGU, and providing psychoeducation as necessary. In such cases, clinicians may assess for PVGU by administering either a short PVGU instrument such as Problem Videogame Playing Scale (PVP; Tejeiro Salguero \& Bersabé Morán, 
2002), or the longer Young's Internet Addiction Scale (YIAS; Young, 1998), depending on time constraints.

Empirical studies of PVGU treatment are very few in number, but there are some studies that discuss treatment of internet addictions in general (Griffiths \& Meredith, 2009). Those studies mainly used cognitive behavioral therapy (CBT), on the basis that internet addiction is similar to impulse-control disorders such as pathological gambling and trichotillomania, and that CBT is an effective treatment for these disorders (Young, 2007). In addition, CBT has been shown to be effective for treating compulsive disorders and substance use disorders (Young, 2007), which also share characteristics with PVGU. As described earlier, impulsivity may play a role in the relationship between ADHD and PVGU, and it is one of the key characteristics of ADHD (Centers for Disease Control and Prevention, 2016), PVGU (Walther et al., 2012), and substance use disorders (Wit, 2009). A potential treatment approach, then, may be to utilize CBT to address the impulsivity of individuals with PVGU.

The current study has a number of strengths, including the large international sample and the more thorough assessment of PVGU than in previous research. However, the results of this study should still be interpreted in light of several limitations. One limitation is the use of an eight-item version of the original PVP scale. As described earlier, one item was excluded due to error, and no data were collected for this item. While it is uncertain how the fit of the model would change if the full PVP scale were used, this eight-item version shared a significant amount of common variance with our other measure of PVGU (the YIAS), suggesting that its performance may be roughly equivalent to the full nine-item version of the scale; nonetheless, comparison studies of 
the two versions are required before stronger conclusions about measurement equivalence can be drawn.

Another limitation of this study pertains to the characteristics of the sample data used in this study. The sample was predominantly male (93\%) and Caucasian $(82.3 \%)$. This makes it difficult to generalize the findings to females and individuals of other racial and ethnic backgrounds. In addition, the data are cross-sectional, meaning that we cannot infer causal relationships among the variables of interest based on the current study. The data were also collected via self-report, without validity checks for accuracy of responding; therefore, the accuracy of reported information depended on each respondent. Respondents may have poor insight about their behavior, or they may be subject to response bias and minimize their problems relating to ADHD symptomatology, smoking behavior, video game use, and/or PVGU. Finally, a self-report instrument was used to assess for ADHD, instead of a diagnostic interview, which may have introduced some response bias. However, it should be noted that the CAARS is a reliable, valid, and widely used instrument in research (Rösler et al., 2006).

\section{Conclusions and Implications}

The current study offers new insight into factors underlying PVGU. ADHD symptomatology, smoking behavior, and the amount of video game use altogether seems to have a significant impact on PVGU. Tracking these variables together may be helpful for clinicians treating clients with PVGU or who are at risk for PVGU. In addition, this study suggests that YIAS and PVP, two scales designed to measure PVGU, do measure the same construct. Either scale may be used as a screener for PVGU, and studies using 
either of these scales may be compared with each other. Future studies may benefit from examining additional variables that help explain PVGU, such as cognitive and affective variables that may directly contribute to PVGU, or contribute to PVGU indirectly through ADHD, smoking, or amount of video game use. 


\section{REFERENCES}

American Psychiatric Association (2000). Diagnostic and statistical manual of mental disorders: DSM-IV-TR. Washington, D.C.: American Psychiatric Association.

American Psychiatric Association (2013). Diagnostic and statistical manual of mental disorders: DSM-5. Washington, D.C.: American Psychiatric Association.

Bioulac, S., Arfi, L., \& Bouvard, M. P. (2008). Attention deficit/hyperactivity disorder and video games: A comparative study of hyperactive and control children. European Psychiatry, 23(2), 134-141.

Brookhaven National Laboratory. (2008). The first video game? Retrieved from https://www.bnl.gov/about/history/firstvideo.php

Brockmyer, J. F. (2015). Playing violent video games and desensitization to violence. Child and Adolescent Psychiatric Clinics of North America, 24(1), 65-77.

Butnik, S. M. (2005). Neurofeedback in adolescents and adults with attention deficit hyperactivity disorder. Journal of Clinical Psychology, 61(5), 621-625.

Centers for Disease Control and Prevention (2016). Facts about ADHD. Retrieved from http://www.cdc.gov/ncbddd/adhd/facts.html

Chan, P. A, \& Rabinowitz, T (2006). A cross-sectional analysis of video games and attention deficit hyperactivity disorder symptoms in adolescents. Ann Gen Psychiatry, 5(16).

Chumbley, J., \& Griffiths, M. (2006). Affect and the computer game player: The effect of gender, personality, and game reinforcement structure on affective responses to computer game-play. CyberPsychology \& Behavior, 9(3), 308-316.

Coëffec, A., Romo, L., Cheze, N., Riazuelo, H., Plantey, S., Kotbagi, G., \& Kern, L. (2015). Early substance consumption and problematic use of video games in adolescence. Frontiers in Psychology, 6(APR), 1-8.

Conners, C. K., Erhardt, D., Epstein, J. N., Parker, J. D., \& Sitarenios, G. (1999). Selfratings of $\mathrm{ADHD}$ symptoms in adults I: Factor structure and normative data. Journal of Attention Disorders, 3, 141-152.

Covey, L. S., Manubay, J., Jiang, H., Nortick, M., \& Palumbo, D. (2008). Smoking cessation and inattention or hyperactivity/impulsivity: A post hoc analysis. Nicotine \& Tobacco Research, 10(12), 1717-1725.

Desai, R. A., Krishnan-Sarin, S., Cavallo, D., \& Potenza, M. N. (2010). Video-gaming among high school students: Health correlates, gender differences, and problematic gaming. Pediatrics, 126(6), e1414-e1424. 
Dyal, S. R., \& Valente, T. W. (2015). A systematic review of loneliness and smoking: Small effects, big implications. Substance Use \& Misuse, 50(13), 1697-1716. http://doi.org/10.3109/10826084.2015.1027933

Entertainment Software Association. (2014). 2014 Essential facts about the computer and video game industry. Retrieved from http://www.theesa.com/wpcontent/uploads/2014/10/ESA_EF_2014.pdf

Entertainment Software Association. (2015). 2015 Essential facts about the computer and video game industry. Social Science Computer Review, 4(1), 2-4. Retrieved from http://www.theesa.com/wp-content/uploads/2015/04/ESA-Essential-Facts2015.pdf

Erhardt, D., Epstein, J. N., Conners, C. K., Parker, J. D. A., \& Sitarenios, G. (1999). Selfratings of ADHD symptoms in adults II: Reliability, validity, and diagnostic sensitivity. Journal of Attention Disorders, 3(3), 153-158.

Fond, G., Guillaume, S., Jaussent, I., Beziat, S., Macgregor, A., Bernard, P., ... Quantin, $X$. (2015). Prevalence and smoking behavior characteristics of nonselected smokers with childhood and/or adult self-reported ADHD symptoms in a smoking-cessation program: A cross-sectional study. Journal of Attention Disorders, 19(4), 293-300.

Fond, G., Loundou, A., Guillaume, S., Quantin, X., Macgregor, A., Lopez, R., ... Boyer, L. (2014). Smoking behavior characteristics of non-selected smokers with childhood attention-deficit/hyperactivity disorder (AD/HD) history: A systematic review and meta-analysis. European Archives of Psychiatry and Clinical Neuroscience, 264(5), 379-89.

Gehricke, J.-G., Hong, N., Whalen, C. K., Steinhoff, K., \& Wigal, T. L. (2009). Effects of transdermal nicotine on symptoms, moods, and cardiovascular activity in the everyday lives of smokers and nonsmokers with attention-deficit/hyperactivity disorder. Psychology of Addictive Behaviors, 23(4), 644-55.

Gehricke, J.-G., Whalen, C. K., Jamner, L. D., Wigal, T. L., \& Steinhoff, K. (2006). The reinforcing effects of nicotine and stimulant medication in the everyday lives of adult smokers with ADHD: A preliminary examination. Nicotine \& Tobacco Research, 8(1), 37-47.

Gentile, D. (2009). Pathological video-game use among youth ages 8 to 18: A national study. Psychological Science, 20(5), 594-602.

Gentile, D. A., Choo, H., Liau, A., Sim, T., Li, D., Fung, D., \& Khoo, A. (2011). Pathological video game use among youths: A two-year longitudinal study. Pediatrics, 127(2), e319-e329. 
Glass, K., \& Flory, K. (2010). Why does ADHD confer risk for cigarette smoking? A review of psychosocial mechanisms. Clinical Child and Family Psychology Review, 13(3), 291-313.

Goodman, A. (1990). Addiction: Definition and implications. British Journal of Addiction, 85(11), 1403-1408.

Google (2014). Google trends [Data file]. Retrieved from http://www.google.com/trends/explore\#geo=US\&date=1\%2F2014\%2012m\&gpro $\mathrm{p}=$ youtube \&cmpt=q\&tz=Etc $\% 2 F G M T \% 2 \mathrm{~B} 8$

Griffiths, M. D., \& Hunt, N. (1995). Computer game playing in adolescence: Prevalence and demographic indicators. Journal of Community \& Applied Social Psychology, 5(3), 189-193.

Griffiths, M. D., \& Meredith, A. (2009). Videogame addiction and its treatment. Journal of Contemporary Psychotherapy, 39(4), 247-253.

Grüsser, S. M. M., Thalemann, R., \& Griffiths, M. D. D. (2007). Excessive computer game playing: Evidence for addiction and aggression? CyberPsychology \& Behavior, 10(2), 290-292.

Humfleet, G. L., Prochaska, J. J., Mengis, M., Cullen, J., Muñoz, R., Reus, V., \& Hall, S. M. (2005). Preliminary evidence of the association between the history of childhood attention-deficit/hyperactivity disorder and smoking treatment failure. Nicotine \& Tobacco Research, 7(3), 453-460.

Kline, R. B. (2005). Principles and practice of structural equation modeling. Guilford Press.

Ko, C.-H., Yen, J.-Y., Yen, C.-F., Lin, H.-C., \& Yang, M.-J. (2007). Factors predictive for incidence and remission of internet addiction in young adolescents: A prospective study. Cyberpsychology \& Behavior, 10(4), 545-51.

Kollins, S. H., McClernon, F. J., \& Van Voorhees, E. E. (2010). Monetary incentives promote smoking abstinence in adults with attention deficit hyperactivity disorder (ADHD). Experimental and Clinical Psychopharmacology, 18(3), 221-8.

Kuss, D. J., \& Griffiths, M. D. (2012). Internet and gaming addiction: A systematic literature review of neuroimaging studies. Brain Sciences, 2(4), 347-374.

Laucht, M., Hohm, E., Esser, G., Schmidt, M. H., \& Becker, K. (2007). Association between ADHD and smoking in adolescence: Shared genetic, environmental and psychopathological factors. Journal of Neural Transmission, 114(8), 1097-1104.

Lerman, C., Audrain, J., Tercyak, K., Hawk, L. W., Bush, A., Crystal-Mansour, S., ... Epstein, L. H. (2001). Attention-Deficit Hyperactivity Disorder (ADHD) 
symptoms and smoking patterns among participants in a smoking-cessation program. Nicotine \& Tobacco Research, 3(4), 353-9.

Lingineni, R. K., Biswas, S., Ahmad, N., Jackson, B. E., Bae, S., \& Singh, K. P. (2012). Factors associated with attention deficit/hyperactivity disorder among US children: Results from a national survey. BMC Pediatrics, 12(1), 50.

Maras, D., Flament, M. F., Murray, M., Buchholz, A., Henderson, K. A., Obeid, N., \& Goldfield, G. S. (2015). Screen time is associated with depression and anxiety in Canadian youth. Preventive Medicine, 73, 133-138.

Mariani, J. J., Khantzian, E. J., \& Levin, F. R. (2014). The self-medication hypothesis and psychostimulant treatment of cocaine dependence: An update. American Journal on Addictions, 23(2), 189-193.

Matthies, S., Holzner, S., Feige, B., Scheel, C., Perlov, E., Ebert, D., ... Philipsen, A. (2013). ADHD as a serious risk factor for early smoking and nicotine dependence in adulthood. Journal of Attention Disorders, 17(3), 176-86.

McClernon, F. J., \& Kollins, S. H. (2008). ADHD and smoking: From genes to brain to behavior. Annals of the New York Academy of Sciences, 1141(1), 131-147.

McClernon, F. J., van Voorhees, E. E., English, J., Hallyburton, M., Holdaway, A., \& Kollins, S. H. (2011). Smoking withdrawal symptoms are more severe among smokers with ADHD and independent of ADHD symptom change: Results from a 12-day contingency-managed abstinence trial. Nicotine and Tobacco Research, 13(9), 784-792.

Newzoo. (2015). Global report: US and China take half of $\$ 113 B N$ games market in 2018. Retrieved from https://newzoo.com/insights/articles/us-and-china-take-halfof-113bn-games-market-in-2018/

Ng, B. D., \& Wiemer-Hastings, P. (2005). Addiction to the internet and online gaming. Cyberpsychology \& Behavior, 8(2), 110-113.

Pallesen, S., Lorvik, I. M., Bu, E. H., \& Molde, H. (2015). An exploratory study investigating the effects of a treatment manual for video game addiction. Psychological Reports, 117(2), 1-6.

Porter, G., Starcevic, V., Berle, D., \& Fenech, P. (2010). Recognizing problem video game use. The Australian and New Zealand Journal of Psychiatry, 44(2), 120128.

Ream, G. L., Elliott, L. C., \& Dunlap, E. (2011a). Patterns of and motivations for concurrent use of video games and substances. International Journal of Environmental Research and Public Health, 8(10), 3999-4012. 
Ream, G. L., Elliott, L. C., \& Dunlap, E. (2011b). Playing video games while using or feeling the effects of substances: Associations with substance use problems. International Journal of Environmental Research and Public Health, 8, 39793998.

Rösler, M., Retz, W., Thome, J., Schneider, M., Stieglitz, R. D., \& Falkai, P. (2006). Psychopathological rating scales for diagnostic use in adults with attentiondeficit/hyperactivity disorder (ADHD). European Archives of Psychiatry and Clinical Neuroscience, 256(SUPPL. 1), 3-11.

Schmidt, M. E., \& Vandewater, E. A. (2008). Media and attention, cognition, and school achievement. Future of Children, 18(1), 63-85.

Shi, L., \& Mao, Y. (2011). Weekend television viewing and video gaming are associated with less adolescent smoking. Journal of Substance Use, 16(2), 109-115.

Tejeiro Salguero, R. A., \& Bersabé Morán, R. M. (2002). Measuring problem video game playing in adolescents. Addiction, 97(12), 1601-1606.

Van Rooij, A. J., Kuss, D. J., Griffiths, M. D., Shorter, G. W., Schoenmakers, M. T., \& Van de Mheen, D. (2014). The (co-)occurrence of problematic video gaming, substance use, and psychosocial problems in adolescents. Journal of Behavioral Addictions, 3(3), 157-65.

Walther, B., Morgenstern, M., \& Hanewinkel, R. (2012). Co-occurrence of addictive behaviours: Personality factors related to substance use, gambling and computer gaming. European Addiction Research, 18(4), 167-174.

Ward, M. F., Wender, P. H., \& Reimherr, F. W. (1993). The Wender Utah rating scale: An aid in the retrospective diagnosis of childhood attention deficit hyperactivity disorder. American Journal of Psychiatry, 150(6), 885-890.

Weinstein, A., \& Weizman, A. (2012). Emerging association between addictive gaming and attention-deficit/ hyperactivity disorder. Current Psychiatry Reports, 14(5), 590-597.

Weiss, M. D., Baer, S., Allan, B. A., Saran, K., \& Schibuk, H. (2011). The screens culture: Impact on ADHD. Attention Deficit and Hyperactivity Disorders, 3(4), 327-34.

Wenzel, H. G., Bakken, I. J., Johansson, A., Götestam, K. G., \& Øren, A. (2009). Excessive computer game playing among Norwegian adults: Self-reported consequences of playing and association with mental health problems. Psychological Reports, 105(3F), 1237-1247.

Widyanto, L., \& McMurran, M. (2004). The psychometric properties of the internet addiction test. Cyberpsychology \& Behavior, 7(4), 443-450. 
Wit, H. De. (2009). Impulsivity as a determinant and consequence of drug use: A review of underlying processes. Addiction Biology, 14(1), 22-31.

Ybarra, M. L., Huesmann, L. R., Korchmaros, J. D., \& Reisner, S. L. (2014). Crosssectional associations between violent video and computer game playing and weapon carrying in a national cohort of children. Aggressive Behavior, 40(4), $345-358$.

Young, K. S. (1998). Internet addiction: The emergence of a new clinical disorder. CyberPsychology \& Behavior, 1(3), 237-244.

Young, K. S. (2007). Cognitive behavior therapy with Internet addicts: Treatment outcomes and implications. Cyberpsychol Behav, 10(5), 671-679.

http://doi.org/10.1089/cpb.2007.9971

Young, K. S. (2009). Understanding online gaming addiction and treatment issues for adolescents. The American Journal of Family Therapy, 37(5), 335-372. 